\title{
Cytokine responses of bovine macrophages to diverse clinical Mycobacterium avium subspecies paratuberculosis strains Harish K Janagama ${ }^{1}$, Kwang il Jeong${ }^{2}$, Vivek Kapur ${ }^{3}$, Paul Coussens ${ }^{4}$ and Srinand Sreevatsan*1,2
}

Address: ${ }^{1}$ Department of Veterinary Population Medicine, University of Minnesota, Saint Paul, MN, USA, ${ }^{2}$ Food Animal Health Research Program, The Ohio State University, Wooster, OH, USA, ${ }^{3}$ Biomedical Genomics Center and Department of Microbiology, University of Minnesota, St. Paul, MN, USA and ${ }^{4}$ Department of Animal Science, Michigan State University, East Lansing, MI, USA

Email: Harish K Janagama - janag001@umn.edu; Kwang il Jeong - Kwang-il.Jeong@tufts.edu; Vivek Kapur - vkapur@umn.edu; Paul Coussens - coussens@msu.edu; Srinand Sreevatsan*-sreev001@umn.edu

* Corresponding author

Published: 14 February 2006

BMC Microbiology 2006, 6:10 doi:10.1186/147|-2180-6-10
Received: 07 October 2005

Accepted: 14 February 2006

This article is available from: http://www.biomedcentral.com/I47I-2/80/6/10

(C) 2006 Janagama et al; licensee BioMed Central Ltd.

This is an Open Access article distributed under the terms of the Creative Commons Attribution License (http://creativecommons.org/licenses/by/2.0), which permits unrestricted use, distribution, and reproduction in any medium, provided the original work is properly cited.

\begin{abstract}
Background: Mycobacterium avium subsp. paratuberculosis (MAP), the causative agent of Johne's disease (JD) persistently infects and survives within the host macrophages. While it is established that substantial genotypic variation exists among MAP, evidence for the correlates that associate specific MAP genotypes with clinical or sub-clinical disease phenotypes is presently unknown. Thus we studied strain differences in intracellular MAP survival and host responses in a bovine monocyte derived macrophage (MDM) system.
\end{abstract}

Results: Intracellular survival studies showed that a bovine MAP isolate (BI0I8) and a human MAP isolate (Hu6) persisted in relatively higher numbers when compared with a sheep MAP isolate (S7565) at 24-hr, 48-hr and 96-hr post infection (PI). MDMs stimulated with BI0I8 up-regulated IL-10 at the transcript level and down-regulated TNF $\alpha$ at the protein and transcript levels compared with stimulations by the S7565 and Hu6. MDMs infected with Hu6 showed a down regulatory pattern of IL-10 and TNF $\alpha$ compared to stimulations by S7565. Cells stimulated with BI0I8 and Hu6 had low levels of matrix metalloprotease-3 (MMP3) and high levels of tissue inhibitor of metalloprotease-I (TIMPI) at 96-hr PI relative to MDMs stimulated by S7565.

Conclusion: Taken together, results suggest that the bovine (BI0I8) and the human (Hu6) MAP isolates lead to anti-inflammatory and anti-invasive pathways in the macrophage environment whereas the sheep (S7565) MAP isolate induces a pro-inflammatory pathway. Thus the infecting strain genotype may play a role in polarizing the host immune responses and dictate the clinicopathological outcomes in this economically important disease.

\section{Background}

Johne's disease (JD) is caused by the intracellular pathogen, Mycobacterium avium subsp. paratuberculosis (MAP). Several molecular techniques have been applied to differentiate and characterize MAP isolates from diverse hosts and geographic locations [1-3]. A recent study applied highly discriminatory molecular markers termed short sequence repeats (SSR) to analyze the diversity among MAP isolates from a variety of hosts [4]. The results provided evidence for interspecies transmission of several 
MAP genotypes with some showing host specificity. Intriguingly, all genotyping studies addressing diversity using a variety of methods show that MAP isolated from human Crohn's disease cases are a subset of MAP genotypes widespread in distribution among animal populations. These findings raise several questions regarding the association of specific genotypes with human disease and/ or chronic sub-clinical versus overt clinical disease in animals. Since no information on disease phenotypes was obtained when the isolates were acquired for genotyping in our laboratory, logical interpretation of genotype-phenotype associations was not possible. In the absence of clinical data associated with genotypes, and a suitable animal model to rapidly identify strain-associated differ- ences, studying MAP interactions in a cellular (macrophage) interphase provides an indirect tool to help dissect the early molecular events that occur during hostpathogen interactions.

Despite the fact that hosts have only a limited number of pathways in which they respond to pathogens, macrophages show both pathogen-specific gene expression profiles and a shared gene expression pattern when infected with diverse bacterial pathogens [5]. An in vitro study of human macrophage responses to a repertoire of genotypically and epidemiologically well defined clinical isolates of Mycobacterium tuberculosis (MTB) showed a strain dependent host response [6]. A more recent study has

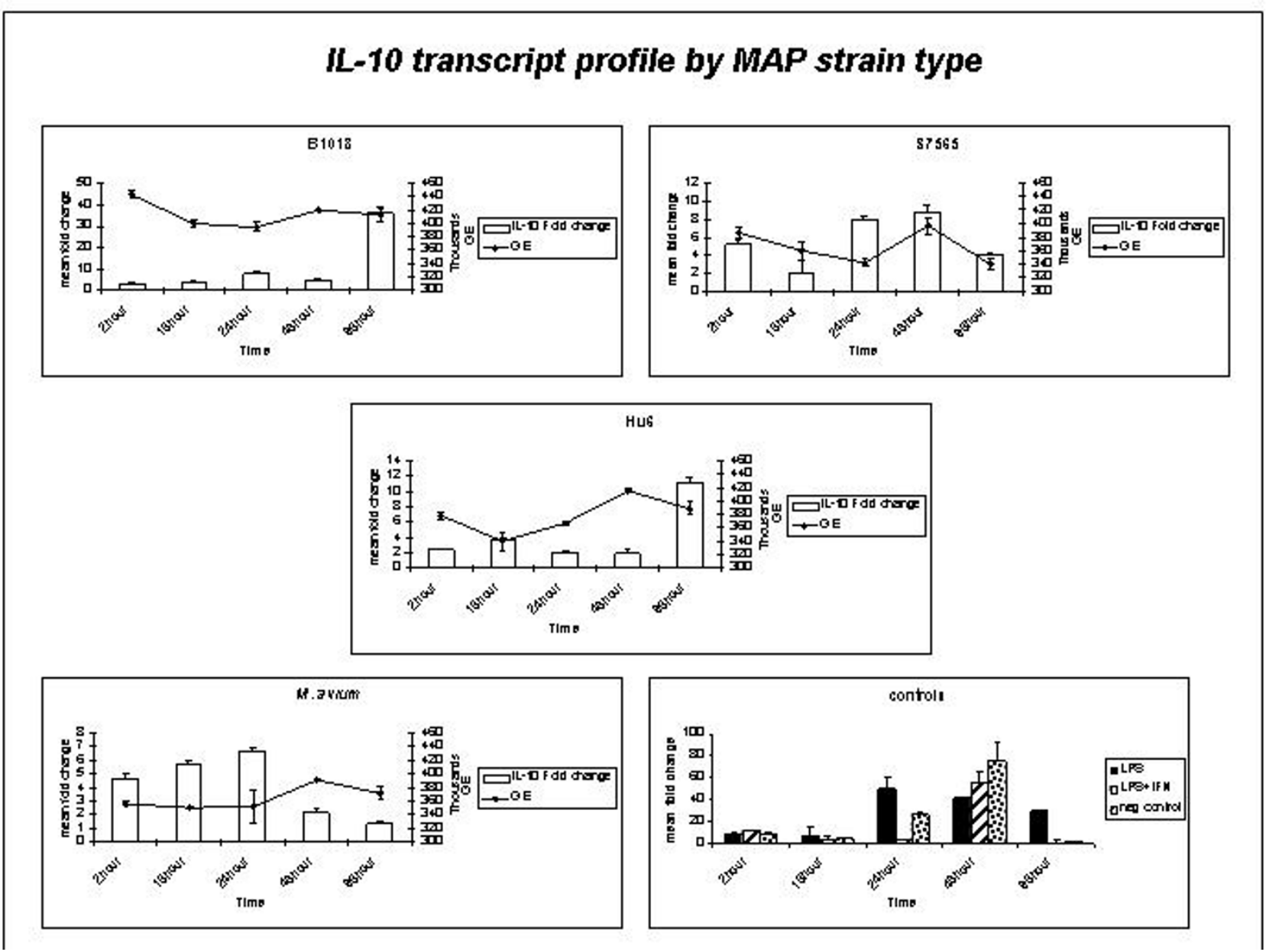

Figure I

IL-I 0 mRNA expressed by MDM cells exposed to $M$. paratuberculosis strains over time was measured by Real time RT PCR and fold change in gene expression relative to $\beta$ actin was calculated by $2-\Delta \Delta C T$ method. Mean fold change in gene expression is plotted on $\mathrm{Y}$-axis (note that the $\mathrm{Y} I$-axis scales have been optimized for magnitude of IL- 10 expression for each strain). Intracellular bacterial numbers based on the amplification of hsp65 were calculated based on genome size of MAP and represented as genome equivalents (GE) on second Y-axis. MDMs stimulated with BI0I8 and Hu6 MAP isolates increased IL-I0 mRNA by 96 hrs $\mathrm{PI}$ relative to cell stimulations by $\mathrm{S7565}$ MAP isolate and M. avium. 


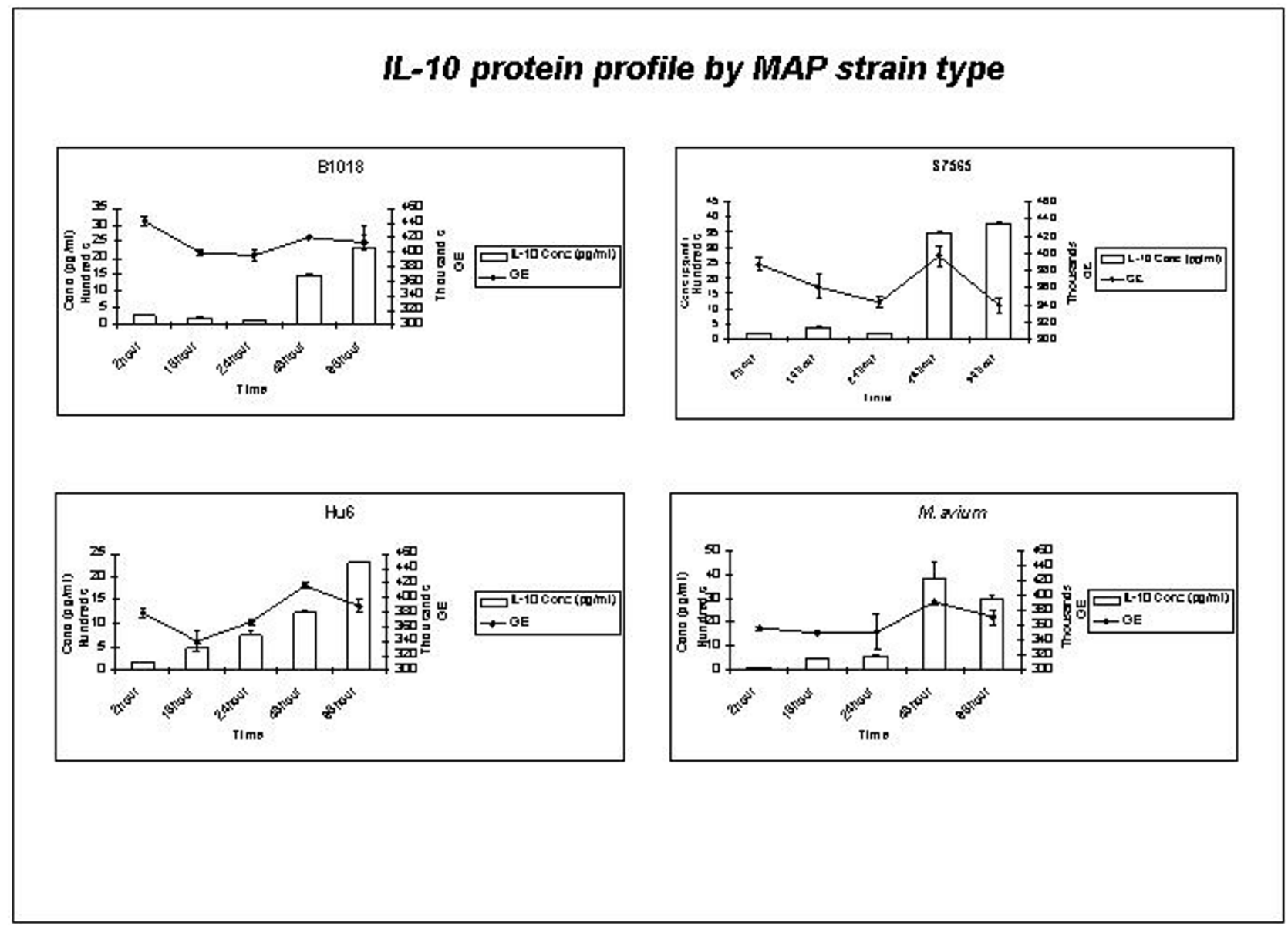

Figure 2

IL-I 0 protein secreted by MDM cells exposed to MAP over time was measured by ELISA. Total amount of protein (pg/ml) is plotted on $\mathrm{Y}$-axis (note that the $\mathrm{YI}$-axis scales have been optimized for magnitude of IL- 10 expression for each strain). Intracellular bacterial numbers were calculated based on genome size of MAP and represented as genome equivalents (GE) on second Y-axis. MDMs stimulated with BI0I8 and Hu6 MAP isolates gradually up regulated IL-I0 secretion from 2-hr until 96-hr PI.

shown a shared and a unique gene expression signature by human macrophages stimulated with four isolates of $M$. avium that varied in growth characteristics [7]. Significant differences in cytokine-chemokine profiles or global gene expression profiles in either well-established cell lines (THP-1 or U937) or peripheral blood mononuclear cells (PBMCs) in response to diverse pathogenic and non pathogenic mycobacteria, have also been documented by several recent studies [8-11]. Taken together, available data in the current literature strongly suggests that macrophages infected with mycobacteria have differential gene expression profiles and that the infecting genotypes may dictate down stream host responses. Surprisingly, there have been no reports so far about comparative analyses of diverse clinical isolates of MAP within a host/host macrophage, which is a well established fact in other mycobac- teria. We believe that this crucial piece of evidence is important in order to understand complex mechanisms underlying the virulence of this economically important pathogen.

Towards these long term goals, in this study we asked if genotypically distinct strains of MAP derived from different host species elicit differential responses in bovine monocyte derived macrophages. To test our hypothesis that there would be no strain-specific variation in host responses, we studied the growth kinetics of genotypically distinct strains of MAP in both BOMAC cells [12] and bovine monocyte derived macrophages (MDM). We compared the modulation of cytokines such as IL-10, TNF $\alpha$ and matrix metalloproteinase (MMP) genes such as MMP3 and MMP9 as a function of infecting genotype. The 


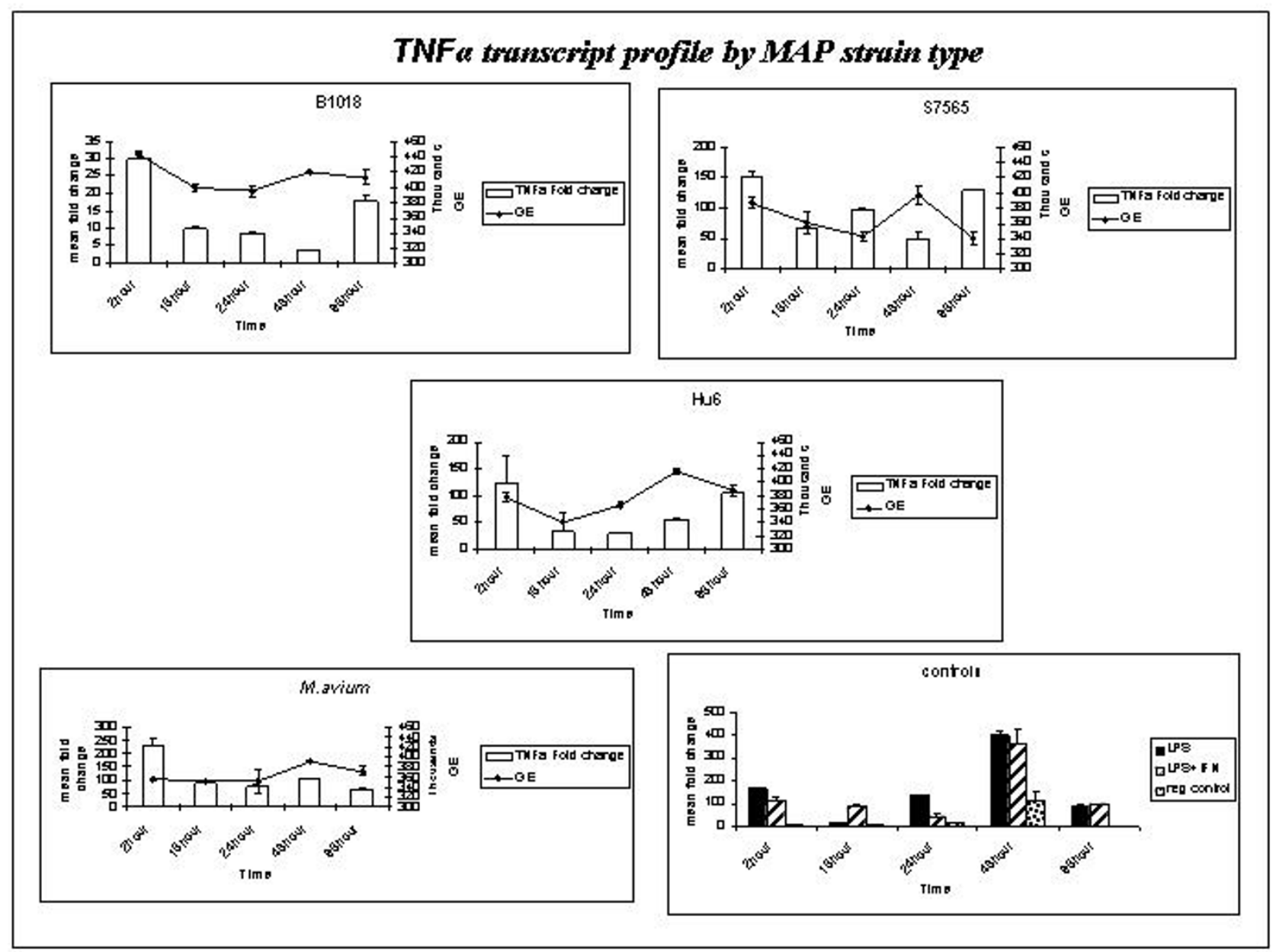

Figure 3

TNF $\alpha$ mRNA expressed by MDM cells exposed to MAP over time was measured by Real time RT PCR and fold change in gene expression relative to $\beta$ actin was calculated by $2^{-\Delta \Delta C T}$ method. Mean fold change in gene expression is plotted on $Y$-axis (note that the $\mathrm{YI}$-axis scales have been optimized for magnitude of IL- 10 expression for each strain). Intracellular bacterial numbers based on the amplification of $h s p 65$ were calculated based on the genome size of MAP and represented as genome equivalents (GE) on second Y-axis. MDMs stimulated with BI0I8 expressed lower levels of TNF $\alpha$ mRNA relative to other cell stimulations.

importance of these cytokines in JD has been reported elsewhere $[13,14]$. Cytokines IL-10 and TNF $\alpha$ were evaluated because the relative balance in expression of these cytokines indicates macrophage activation. PBMCs isolated from cattle infected with JD have been shown to up regulate MMP9 and TIMP after stimulation with MAP [15]. MMPs when secreted in lower quantities help in leukocyte migration but when secreted in larger quantities cause tissue destruction [16]. A balance between MMP and TIMP is important in the extent of tissue degradation [16]. In summary, in this study we report a differential response of bovine monocyte derived macrophages to a variety of MAP isolates.

\section{Results}

Intracellular survival kinetics of MAP strains

B1018 (bovine MAP isolate) was efficiently phagocytosed by bovine MDMs and persisted at fairly high numbers when compared to other isolates at all time points (Figures 1, 2, 3, 4). S7565 (sheep MAP isolate) decreased in bacterial numbers until 24-hr PI, started to multiply by 48-hr PI and dropped in total intracellular bacterial num- 


\section{TNFa protein profile by MAP struin type}
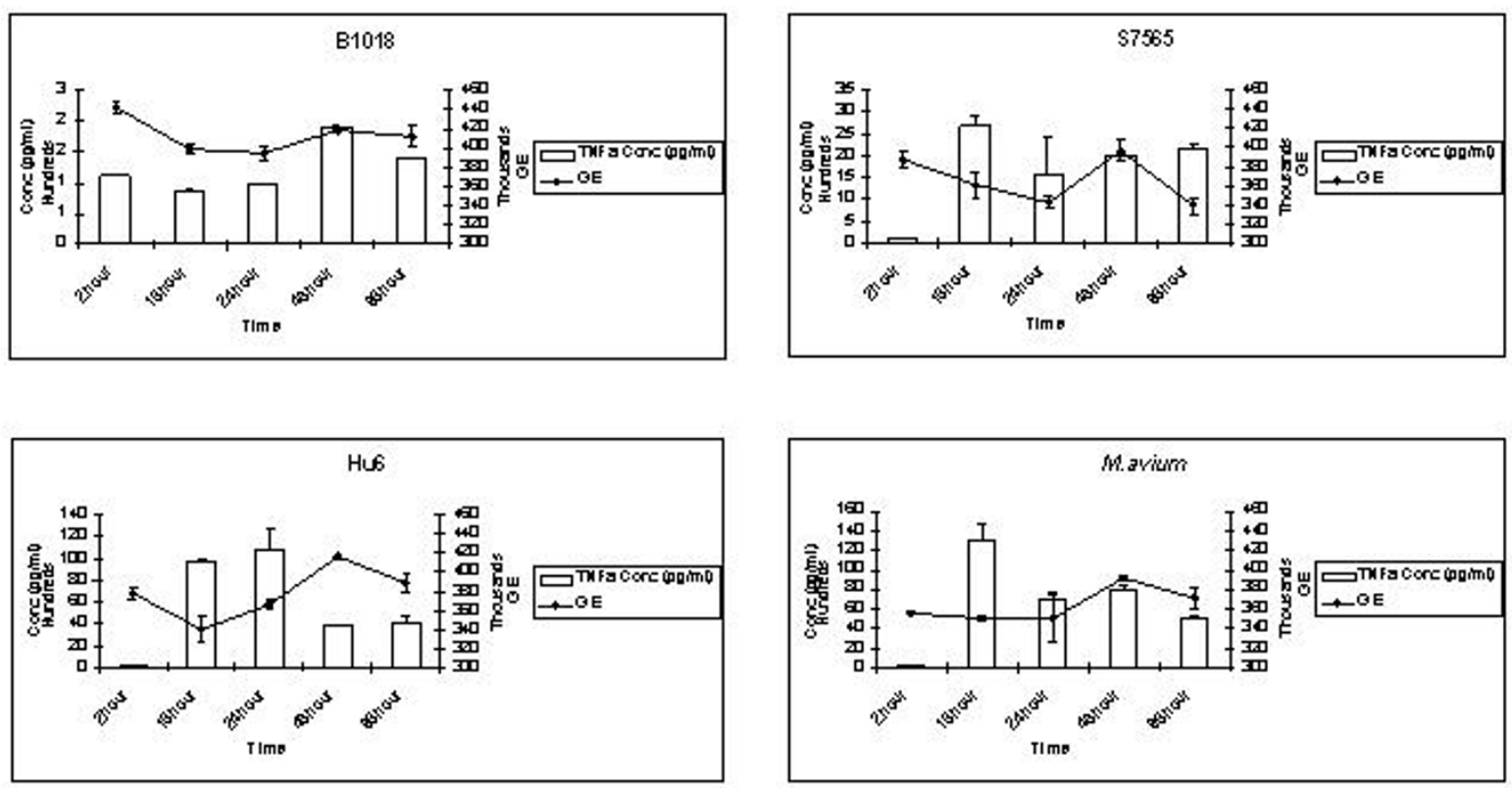

\section{Figure 4}

TNF $\alpha$ protein secreted by MDM cells exposed to MAP over time was measured by ELISA. Total amount of protein (pg/ml) is plotted on $\mathrm{Y}$-axis (note that the $\mathrm{YI}$-axis scales have been optimized for magnitude of TNF $\alpha$ expression for each strain). Intracellular bacterial numbers were calculated based on the genome size of MAP and represented as genome equivalents (GE) on second $\mathrm{Y}$-axis. MDMs stimulated with BI0I8 secreted low amounts of TNF $\alpha$ protein relative to other cell stimulations.

bers by 96-hr PI. Hu6 (human MAP isolate) declined in numbers until 16-hr post infection and began replicating until 48-hr after infection and started to drop until 96-hr PI. M. avium showed a persistent trend until 24 hrs after infection of MDMs and replicated thereafter, until $48 \mathrm{hrs}$ post infection.

In BOMAC cells 57565 multiplied more rapidly and stayed in higher numbers at $96 \mathrm{hr}$ PI relative to B1018. However, in bovine MDM cells B1018 was efficiently internalized and stayed in higher numbers relative to S7565 and Hu6 MAP isolates (data not shown).

\section{IL-I 0 expression profile}

As intracellular bacteria began replication (2-96 hr PI), MDMs stimulated with bovine (B1018) and human
(Hu6) MAP isolates up-regulated IL-10 mRNA (fig 1) and protein (fig 2) levels over the entire infection period and this peaked from 48 -hr to 96-hr PI. There was a positive correlation between IL-10 mRNA gene expression and IL10 protein secretion (data not shown) observed in the cells stimulated with B1018 and Hu6. Cells stimulated with S7565 and $M$. avium down regulated IL-10 mRNA by 96-hr PI (fig 1). Cells stimulated with M. avium showed a gradual increase in IL-10 protein secretion until 48-hr PI and started to drop until 96-hr PI (fig 2). Interestingly, cells stimulated with $\mathrm{S} 7565$ showed a sustained increase in IL-10 protein secretion until 96-hr PI (fig 2).

\section{TNF $\alpha$ expression profile}

MDMs stimulated with B1018 and Hu6 isolates showed a down regulatory trend in $\mathrm{TNF} \alpha \mathrm{mRNA}$ expression from 2- 
Table I: LSMean values with Standard errors of the MMP3 gene transcripts. Depicts the LSMean values with Standard errors of the MMP3 gene transcripts expressed by macrophages over time and measured by Real Time RT PCR as described in materials and methods. Values with same superscript (a, b, c, p, q, r) indicate significant differences among the strains at that time point PI.

\begin{tabular}{|c|c|c|c|c|c|}
\hline \multirow[t]{2}{*}{ Strain } & \multicolumn{5}{|c|}{ Time post infection } \\
\hline & 2 hour & 16 hour & 24 hour & 48 hour & 96 hour \\
\hline $\mathrm{B} 1018$ & $44.3 \pm 4.77$ & $574.6 \pm 315^{a}$ & $259.4 \pm 50.5 p$ & $121.6 \pm 26$ & $72.3 \pm 24.3$ \\
\hline S7565 & $55.6 \pm 5.17$ & $25.7 \pm 6.6^{b}$ & $10057 \pm 2104 \mathrm{p}, q, \mathrm{r}$ & $5451 \pm 453$ & $406 \pm 17.9$ \\
\hline Hu6 & $5.4 \pm 0.2$ & $25 \pm 3.9 c$ & $134 \pm 19.6 r$ & $319 \pm 6.2$ & $61.2 \pm 10.7$ \\
\hline M. avium & $22.3 \pm 2.2$ & $6794 \pm 133^{a, b, c}$ & $846 \pm 1079$ & $166.7 \pm 22.8$ & $149 \pm 3.6$ \\
\hline $\mathrm{PClx}$ & $56.6 \pm 8.5$ & $555 \pm 51.6$ & $26180 \pm 4595$ & $16742 \pm 2938$ & $1840 \pm 678$ \\
\hline $\mathrm{PC} 2 \mathrm{y}$ & $188.8 \pm 39$ & $15825 \pm 2625$ & $8164 \pm 160$ & $35563 \pm 3307$ & $554 \pm 8.1$ \\
\hline$N C^{z}$ & $14.8 \pm 7.5$ & $43.9 \pm 3.6$ & $398 \pm 29.4$ & $2629 \pm 77.3$ & $1.7 \pm 0.18$ \\
\hline
\end{tabular}

$\mathrm{x}$ indicates positive control I (PCI) - cells stimulated with LPS

$y$ indicates positive control 2 (PC2) - cells stimulated with LPS in conjunction with recombinant bovine Interferon gamma

$\mathrm{z}$ indicates negative control (NC) - unstimulated cells

hr to 48-hr PI that switched course to an up-regulatory trend from 48-hr until 96-hr PI (fig 3). Cells stimulated with B1018 gradually up-regulated TNF $\alpha$ protein secretion from 2-hr until 48-hr PI that dropped thereafter (fig 4). Cells stimulated with Hu6 increased TNFa protein secretion until 24-hr PI that showed a down-regulatory trend until 96-hr PI (fig 4). Cells stimulated with S7565 up-regulated TNF $\alpha$ mRNA and protein levels by $96-\mathrm{hr}$ PI (fig 3 \&4). At 96-hr PI, the magnitude of TNF $\alpha$ mRNA and protein level was significantly lower $(P<0.05)$ in cells stimulated with B1018 relative to cell stimulations by S7565, Hu6 and M. avium (fig 3). Although, cells stimulated with $M$. avium down regulated TNFo protein secretion from 16-hr until 96-hr PI, the amount of protein detected was significantly higher $(P<0.05)$ relative to other stimulations (fig 4).

\section{MMP3 mRNA expression}

MDMs stimulated with B1018 increased the production of MMP3 mRNA at 16-hr which was followed by a rapid decline until 96 hrs PI (table 1). Cells stimulated with
S7565 produced a peak level of MMP3 at 24-hr that declined by 96-hr. While MMP3 mRNA production by cells stimulated with B1018 was high at 16-hr relative to cells stimulated by $\mathrm{S} 7565$ and Hu6, the data was not statistically significant $(P=1.0)$. At 24 -hr there was a significant increase $(P<0.05)$ in the production of MMP3 mRNA by cells stimulated with $\mathrm{S} 7565$ relative to other stimulations. There was a gradual up-regulation of MMP3 mRNA production by MDMs stimulated with Hu6 until 48 hrs and declined by 96-hr.

\section{MMP9 mRNA expression}

Cells stimulated with B1018 showed lower levels of MMP9 mRNA production at 48-hr and 96-hr PI relative to cell stimulations with other MAP isolates (table 2). Cells stimulated with $\mathrm{S} 7565$ had a peak MMP9 mRNA production at 48 -hr after infection, which was significantly higher $(P<0.05)$ when compared with stimulations by other MAP isolates (table 2). Cells stimulated with Hu6 also showed an up-regulatory trend in MMP9 mRNA production until 96-hr (table 2). Cells stimulated with Hu6

Table 2: LSMean values with Standard errors of the MMP9 gene transcripts. Depicts the LSMean values with Standard errors of the MMP9 gene transcripts expressed by macrophages over time and measured by Real Time RT PCR as described in materials and methods. Values with same superscript (a, b, c, d) indicate significant differences among the strains at that time point PI.

\begin{tabular}{|c|c|c|c|c|c|}
\hline \multirow[t]{2}{*}{ Strain } & \multicolumn{5}{|c|}{ Time post infection } \\
\hline & 2 hour & 16 hour & 24 hour & 48 hour & 96 hour \\
\hline $\mathrm{B} 1018$ & $3 \pm 0.47$ & $|8.2 \pm 0.8|$ & $82.7 \pm 19.2$ & $109.8 \pm 12.3^{c}$ & $66.6 \pm 10^{d}$ \\
\hline S7565 & $1.4 \pm 0.09$ & $0.07 \pm 0.03$ & $130.8 \pm 8.3^{a}$ & $760.3 \pm 26 c$ & $117.4 \pm 6.3$ \\
\hline Hu6 & $4.2 \pm 0.72$ & $10.9 \pm 0.64$ & $45.9 \pm 2.25^{\mathrm{a}, \mathrm{b}}$ & $321.3 \pm 29.8$ & $629 \pm 49.2$ \\
\hline M. avium & $0.94 \pm 0.27$ & $53.2 \pm 1.3$ & $131.3 \pm 10.9 b$ & $318.5 \pm 38.9$ & $220.6 \pm 9.7^{d}$ \\
\hline $\mathrm{PClx}$ & $0.7 \pm 0.06$ & $49.4 \pm 3.1$ & $648 \pm 9.5$ & $365.8 \pm 8.9$ & $19.8 \pm 1.8$ \\
\hline $\mathrm{PC} 2 \mathrm{y}$ & $0.44 \pm 0.01$ & $65 \pm 2.2$ & $294 \pm 10$ & $1564 \pm 91.9$ & $5.4 \pm 2.2$ \\
\hline$N C^{z}$ & $0.3 \pm 0.07$ & $2.07 \pm 0.2$ & $5.6 \pm 2.7$ & $0.1 \pm 0.01$ & $6.7 \pm 0.23$ \\
\hline
\end{tabular}

$\mathrm{x}$ indicates positive control I (PCI) - cells stimulated with LPS

$y$ indicates positive control 2 (PC2) - cells stimulated with LPS in conjunction with recombinant bovine Interferon gamma

$\mathrm{z}$ indicates negative control (NC) - unstimulated cells 
Table 3: LSMean values with Standard errors of the TIMPI gene transcripts. Depicts the LSMean values with Standard errors of the TIMPI gene transcripts expressed by macrophages over time and measured by Real Time RT PCR as described in materials and methods.

\begin{tabular}{cccccc}
\hline Strain & \multicolumn{5}{c}{ Time post infection } \\
\hline & 2 hour & 16 hour & 24 hour & 48 hour & 96 hour \\
\hline B1018 & $6.45 \pm 0.28$ & $16.65 \pm 8.57$ & $6.2 \pm 0.09$ & $11.63 \pm 1.42$ & $45.9 \pm 8.74$ \\
S7565 & $12.4 \pm 1.88$ & $2 \pm 0.67$ & $5.74 \pm 1.9$ & $9.26 \pm 0.5$ & $25.2 \pm 0.25$ \\
Hu6 & $3.12 \pm 0.79$ & $0.87 \pm 0.16$ & $1.1 \pm 0.34$ & $2.3 \pm 0.3$ & $34.6 \pm 5.7$ \\
M. avium & $2.62 \pm 0.18$ & $3.2 \pm 1.5$ & $3.5 \pm 0.07$ & $4.2 \pm 0.36$ & $6.4 \pm 1.25$ \\
PCI & $6.1 \pm 0.6$ & $3.8 \pm 0.04$ & $10.7 \pm 1.52$ & $36.4 \pm 3.39$ & $159.7 \pm 1.57$ \\
PC2y & $6.3 \pm 0.34$ & $24 \pm 1.53$ & $2.2 \pm 0.65$ & $52.3 \pm 6.91$ & $38.6 \pm 5.1$ \\
NCz & $6.2 \pm 0.91$ & $26.6 \pm 3.91$ & $49.8 \pm 23.26$ & $584.2 \pm 71.4$ & $8.1 \pm 3.46$ \\
\hline
\end{tabular}

$\mathrm{x}$ indicates positive control I (PCI) - cells stimulated with LPS

$y$ indicates positive control 2 (PC2) - cells stimulated with LPS in conjunction with recombinant bovine Interferon gamma

$\mathrm{z}$ indicates negative control (NC) - unstimulated cells

had significantly $(\mathrm{P}<0.05)$ low MMP9 mRNA levels relative to cells stimulated with S7565 at 24-hr and 48-hr PI (table 2).

\section{TIMPI mRNA expression}

LSMean values of TIMP1 mRNA levels suggested that MDMs stimulated with B1018 showed higher levels relative to cell stimulations by S7565 (data not statistically significant) $(p=1.0)$. There was a peak production of TIMP1 mRNA observed at $96-\mathrm{hr}$ in MDMs stimulated with B1018 (table 3).

\section{Discussion}

Macrophages are the first line of host defense against any invading bacteria. Despite the fact that macrophages offer a hostile environment to several pathogenic bacteria, MAP is able to persistently survive and replicate within the phagosome environment of host macrophages. Studying the biochemical processes operating at the host-pathogen interface will help elucidate the mechanisms by which $M A P$ has developed expertise to survive and replicate inside macrophages. Over the years many researchers have employed techniques such as microarray, semiquantitative PCR, Q-RT-PCR to study the gene expression profiles in a cellular model after infection with pathogenic mycobacteria including type strains of MAP $[9,17,18]$. However, a possible MAP genotype-disease phenotype association has not been established despite the evidence that there is diversity in the genotypes of MAP strains isolated from several different hosts $[19,20]$.

In the absence of a well characterized experimental animal model to study host pathogen interactions of MAP in $\mathrm{JD}$, cellular models have served as a helpful surrogate to researchers [21-24]. While BOMAC cells provide an easy to use immortalized cell line to study host-pathogen interactions, our studies with this cell line support earlier observations by Sager et al. [25] further highlighting that this bovine monocytoid cell line may differ in their behavior compared with MDMs. Thus, we chose to characterize MAP strain dependent host response only in bovine MDM cells.

Bovine monocyte derived macrophages infected with MAP have been previously employed to study changes in cytokine profiles $[21,26]$. In the present study we have demonstrated a MAP genotype dependent phenotype characterized by differences in the cytokine profiles such as IL-10, TNF $\alpha$ and MMPs in MDMs. The importance of IL-10 and TNF $\alpha$ in JD has been reported elsewhere $[13,14]$. IL-10 inhibits macrophage activation and is one of the major anti inflammatory cytokines [27]. TNFa is a major inflammatory cytokine produced by activated macrophages and is involved in controlling bacterial replication [28-30].

Our results based on the data generated using MDM cells obtained from two different animals consistently showed that B1018 (bovine MAP isolate) efficiently entered and remained in higher numbers within MDM cells relative to other MAP isolates. Cells stimulated with B1018 up-regulated expression of IL-10 mRNA $(P<0.005)$ while expression of TNF $\alpha$ mRNA was down-regulated relative to other MAP isolates. This was also evident in the relatively low proteins identified in the culture supernatant. Previous studies also reported a similar phenotype for the ATCC 19698 strain of MAP in bovine macrophages [21]. Khaleifh et. al [31] reported an up regulatory pattern of IL-10 secretion in bovine macrophages following infection with a type strain of MAP which is consistent with our findings, although the magnitude of up regulation at the protein level was much lower compared with their IL-10 levels. When compared to B1018, Hu6 and S7565 strains significantly down regulated IL-10 mRNA and up regulated TNFa mRNA. MDMs stimulated with S7565 and Hu6 $M A P$ strains had significantly high amounts $(P<0.05)$ of 
TNF $\alpha$ and IL-10 secreted into culture supernatants relative to B1018 strain. A similar proinflammatory response by dendritic cells to whole cell MAP (strain 316F) infection has been recently demonstrated [32]. The study also documented that stimulation of dendritic cells by a recombinant immunodominant antigen of MAP included severe anti-inflammatory responses invoking the hypothesis that the differential in macrophage responses seen in our study may have occurred due to differences in expression of specific virulence genes by the strains studied. Our studies with SSR analysis $[4,19,33,34]$ and SNP analysis (Zhu and Sreevatsan, unpublished) suggest that specific genotypes may be associated with subclinical disease while others may lead to clinically overt disease. Additionally, in vitro analysis of MAP survival within primary macrophage cells in the present study show clear distinction in entry, survival and persistence as a function of genotypes. DNA microarray analysis of the genome content of MAP isolates employed in this study using MAA104 array revealed that several large sequence polymorphisms (LSPs) were missing in S7565 when compared to B1018 (Semret $M$, presented at $8^{\text {th }}$ International Colloquium on Paratuberculosis). While this may explain the variations between sheep (S7565) and bovine (B1018) isolates, the variations in host response to bovine (B1018) or human (Hu6) genotypes of MAP may exist in SNPs and/or variations in bacterial gene regulation within the host. Confirmation of this finding will require analysis of a larger genotypically diverse collection for both host and pathogen gene expression. Comparisons of infections with a type strain of MAP and $M$. avium avium in bovine MDMs have revealed an increased expression of TNFa in cells infected with $M$. avium avium and a down regulation of IL10 [21]. The M. avium intracellulare strain employed in our study showed similar trends in TNF $\alpha$ production when compared to other MAP strains studied. However, an increased IL-10 level was detected in culture supernatants infected with $M$. avium intracellulare compared to other strains at 96-hr PI. The differences observed could be because the $M$. avium intracellulare strain utilized in this study was unique in that this strain carried IS900, an insertion element that was once considered unique to MAP.

Matrix metalloproteinases (MMPs) are a family of calcium-dependent proteinases [35] involved in cell migration, tissue remodeling and destruction. Tissue inhibitors of MMP (TIMP) inhibit the activity of MMP. A balance between MMP and TIMP produced at the site of inflammation influences the ability of immune cells to migrate and the amount of tissue destruction caused [36]. PBMCs isolated from cattle infected with JD have been documented to up-regulate MMP9 and TIMP after stimulation with MAP [15,37]. MMP and TIMP are reported to play a functional role in infections caused by pathogenic mycobacteria [38]. In our study, cells stimulated with B1018 down-regulated MMP9 while up-regulating TIMP1 production relative to MDMs stimulated with $\mathrm{Hu} 6$ and S7565 strains. This is consistent with the idea that these MAP genotypes (finger print: 7G4GGT) lead to an anti-inflammatory and anti-invasive milieu allowing their persistence and survival within macrophages. THP-1 cells infected with MTB have shown significant production of MMP9 and TIMP1 but not MMP1 [16]. MMP9 when secreted at low levels aid leukocyte migration to sites of inflammation. However, in large amounts, MMP9 causes tissue destruction [16]. It has also been shown that TNFa production at the site of inflammation correlates with MMP9 production [39]. Our observations are consistent with the idea that S7565 strain may elicit a relatively more invasive pathway during infection. Taken together, our studies demonstrate a MAP genotype-dependent response in a bovine monocyte derived macrophage model.

\section{Conclusion}

The present findings provide key insights into the MAP genotype-disease phenotype associations. Further analysis of this complex "ancient dialogue" between MAP and macrophages derived from its natural host (bovines) will help elucidate the pathogenesis associated with different genotypes isolated from diverse host species. These studies will aid in understanding the proximal events involved in the progression of JD and the virulence of MAP isolates thus enabling design of early intervention strategies. Future studies with a broader range of MAP isolates with common and unique genotypes associated with JD are warranted.

\section{Methods}

Preparation of monocyte derived macrophages (MDM)

Two colostrum-deprived Holstein bull calves obtained from a Johne's disease free herd served as a source for peripheral blood and MDMs. The calves were tested 4 and 8 weeks after birth by fecal culture and serum ELISA and were confirmed to be JD free. The protocol used for the preparation of MDMs is described elsewhere [40]. Briefly, peripheral blood was drawn from jugular vein into acidcitrate dextrose containing vacutainers (BD Vacutainer, Rutherford, NJ). Blood was centrifuged at $2000 \mathrm{rpm}$ for 20 minutes to obtain a clean buffy coat. Buffy coats were re-suspended in sterile $1 \times$ PBS (1:10 dilution) and overlaid on Histopaque (Sigma Aldrich, St. Louis, Mo) following manufacturer's recommendations. The tubes were centrifuged at $400 \times \mathrm{g}$ for 30 minutes at room temperature to separate mononuclear cells from other polymorphonuclear leukocytes. Mononuclear cells from the interphase were harvested carefully using a sterile Pasteur pipette and transferred to a second sterile 50-ml conical tube. The cells were washed with $10-\mathrm{ml}$ of $1 \times$ PBS at $250 \times \mathrm{g}$ for $10 \mathrm{~min}$ utes. Supernatant was discarded and the cell pellet was resuspended in a small volume of $1 \times$ PBS. The mononuclear 
cells were transferred to TEFLON jars (Savillex Corporation, Minnetonka, MN) containing RPMI 1640 medium supplemented with L-glutamine, HEPES and 20\% autologous serum. The jars were incubated at $37^{\circ} \mathrm{C}, 95 \%$ air and $5 \% \mathrm{CO}_{2}$ for 4 days. After four days monocytes differentiated and became larger in size. Differentiated monocytes were counted using a hemacytometer and seeded onto the tissue culture plates at appropriate dilutions and incubated at $37^{\circ} \mathrm{C}, 95 \%$ air and $5 \% \mathrm{CO}_{2}$ for 2 hours. Plates were washed twice with sterile $1 \times$ PBS to remove the nonadherent cells. The adherent cells were used for all in-vitro infections.

\section{M. paratuberculosis isolates}

The selected MAP strains included B1018 (SSR fingerprint: 7G4GGT9nG), S7565 (SSR fingerprint: 15G3GGT), Hu6 (SSR fingerprint: 7G5GGT11nG) and Ma6043 (IS900 positive isolate identified as M. avium intracellulare by multiple target analyses; no SSR data) (11). B1018 was isolated from a cow with clinical JD and carried a fingerprint which is common to about $12 \%$ of bovine M. paratuberculosis strains in a national collection (Harris and Sreevatsan, Unpublished) and in greater than $45 \%$ of isolates from Ohio (21), S7565 was isolated from sheep and Hu6 was isolated from a Crohn's disease patient.

\section{Bacterial cultures}

All the MAP cultures were incubated at $37^{\circ} \mathrm{C}$ on MB7H9 plates supplemented with OADC enrichment medium and Mycobactin J. After 3-4 weeks of growth on MB7H9 plates, cultures were confirmed to be free of other contaminating organisms as determined by nil growth on BHI or blood agar plates incubated overnight at $37^{\circ} \mathrm{C}$. Few colonies from MB7H9 plate cultures were inoculated into MB7H9 broth culture supplemented with OADC enrichment medium and Mycobactin $\mathrm{J}$ and incubated at $37^{\circ} \mathrm{C}$ for 3 days to achieve actively growing MAP. Three day-old cultures were used to obtain an optical density at $600 \mathrm{~nm}$ $\left(\mathrm{OD}_{600}\right)$ to determine the colony forming units (cfu) of bacteria using the formula: 0.3 at OD600 $=10^{9} \mathrm{cfu} / \mathrm{ml}$, and applied in all in vitro infections of bovine MDM. Bacteria were used at a 5:1 multiplicity of infection.

\section{Experimental design}

MDM monolayers were grown on six well tissue culture plates. Cells were stimulated with three MAP isolates (B1018: bovine, S7565: sheep, and Hu6: human) and one IS900 positive non-MAP isolate (6043: identified as $M$. avium intracellulare). Lipopolysachharide (LPS; $100 \mu \mathrm{g} /$ $\mathrm{ml}$ ) (Sigma Aldrich, St. Louis, Mo) stimulated and LPS $(100 \mu \mathrm{g} / \mathrm{ml})$ in conjunction with recombinant bovine IFN $\gamma(14 \mathrm{ng} / \mathrm{ml})$ (Serotec, Raleigh, NC) stimulated cells served as positive controls where as, nil stimulated MDM served as negative controls in the experiment. All the stimulations were carried out in triplicates and were per- formed simultaneously. Cell stimulations were repeated twice on MDMs from each animal to evaluate consistency in the data generated. The culture plates were incubated at $37^{\circ} \mathrm{C}, 95 \%$ air and $5 \% \mathrm{CO}_{2}$ until used. At each time point (2-hr, 16-hr, 24-hr, 48-hr and 96-hr) cells and culture supernatants from all the treatments were harvested. The culture supernatant was collected and stored at $-70^{\circ} \mathrm{C}$ until used for ELISA. Monolayers were immediately washed twice with sterile, pyrogen-free $1 \times$ PBS and used in RNA extractions.

\section{RNA extraction and real time Q-RT-PCR}

RNA extractions were carried out using TRIzol reagent (Invitrogen, Carlsbad, CA) following manufacturers' recommendations. All the RNA samples were treated with RNAse free DNAse I (Ambion, Austin, TX) according to manufacturer's recommendations and stored at $-70^{\circ} \mathrm{C}$ until utilized in QRT-PCR. Prior to their use, RNA was assessed for the quality and quantity using a spectrophotometer (GeneQuant pro by Amersham Bio sciences Corp, Piscataway, NJ). Subsequently, all the samples were diluted using nuclease free water at a concentration of 10 $\mathrm{ng} / \mu \mathrm{l}$. Later, Real time Q-RT-PCR was performed using Light Cycler system (Roche Diagnostics, Indianapolis, IN). Single step RT PCR was performed using Quantitect SYBR Green RT PCR kit (Qiagen Inc., Valencia, CA). Briefly, each reaction mixture contained $10 \mu \mathrm{l}$ of master mix, $0.2 \mu$ l of RT mix, $2 \mu$ l of template RNA and gene specific (IL-10, TNFa, MMP3, MMP9, or TIMP1) primers. Reactions were performed in $20 \mu \mathrm{l}$ light cycler capillaries (Roche, Indianapolis, IN). Primers used to analyze all the transcripts have been reported else where. The Q-RT-PCR data was analyzed by using $2^{-\Delta \Delta C T}$ method as previously described $[41,42]$.

\section{Survival analysis of MAP strains}

MDMs or BOMAC cells [12] were infected with three MAP isolates and an M. avium at an MOI of 1:5 as described above. All the stimulations were carried in triplicates and were performed simultaneously. Infected cells were incubated at $37 \mathrm{C}, 5 \% \mathrm{CO}_{2}$ until desired. At each time point $(0$, $2,16,24,48$ and $96 \mathrm{hrs}$ post infection) culture plates were removed and monolayers were vigorously washed for three times with $1 \times$ PBS to get rid of loosely adherent cells and external bacteria. DNA from the monolayers was extracted using TRIzol (Invitrogen, Carlsbad, CA) following manufacturer's recommendations.

Briefly, Monolayers were lysed on culture plates using 1 $\mathrm{ml}$ of Trizol reagent. Samples were then mixed with zirconium beads $(0.1 \mathrm{~mm})$ and homogenized for 3 minutes using mini bead beater (Biospec products, Bartlesville, OK). This effectively released mycobacterial DNA. Later, samples were mixed with $200 \mu \mathrm{l}$ of chloroform and centrifuged at $1500 \mathrm{rpm}$ for 5-min at 4C. Pellet was washed 
twice with $0.1 \mathrm{M}$ sodium citrate in $10 \%$ ethanol. Finally pellet was washed with $75 \%$ ethanol, air dried and dissolved in sterile distilled water and stored at $-20 \mathrm{C}$ until used. DNA was used in the real time PCR to quantitate $h s p 65$ gene of MAP. Since $h s p 65$ is a single copy gene, it provided a good estimate of the total number of organisms that survived macrophage infection over time. All the amplifications were carried out in Light cycler (Roche, Indianapolis, IN) using quantitect SYBR Green (Qiagen, Valencia, CA).

Briefly, each reaction mixture contained $10 \mu \mathrm{l}$ of master mix, $2 \mu \mathrm{l}$ of template DNA and gene specific primers (forward - 5' GCC GCT GCT GAT CAT CGC CGA 3') (reverse - 5' CCT TGG TGA CGA CCT T 3'). Reactions were performed in $20 \mu \mathrm{l}$ light cycler capillaries (Roche, Indianapolis, IN). Obtained ct (crossing time points) values from the real time PCR were converted to genome equivalents. Based on the genome size of MAP one genome equivalent was calculated to be equal to about $9.9 \mathrm{fmg}$ of MAP DNA.

\section{Development of hsp65 standard for quantification purposes}

DNA extracted from the broth cultures of MAP was pooled and the concentrations were determined. Five, ten-fold dilutions of the DNA was made and used as template in the real time PCR for amplification of hsp65 gene. Obtained ct values were imported onto an Excel spread sheet. Ct vales were plotted against genome equivalents ( $\mathrm{Y}$ axis) and regression analysis was performed. This regression equation was used to estimate the bacterial numbers (as genome equivalents) in all treatment samples.

\section{Quantitation of extracellular cytokine production by ELISA}

Cytokine sandwich ELISA was used to detect IL-10 and TNF $\alpha$ from the culture supernatants. The protocol was adopted and modified to our conditions as described $[43,44]$. Briefly, 96 well micro titer plates (NUNC, Rochester, NY) were coated with mouse anti bovine IL-10 (Serotec Inc, Raleigh, NC) or mouse anti bovine TNF $\alpha$ (generous gift from Dr. Paape, USDA, Ames, IA) for overnight at $4{ }^{\circ} \mathrm{C}$. Next day plates were washed with PBS Tween $20(0.05 \%)$ and blocked with PBS/BSA (0.5\%) for one hour at room temperatures. Culture supernatants were added to the plates. The standard protein was serially diluted and added to the corner wells. Standard protein for TNF $\alpha$ was purchased from Endogen where as standard protein for IL-10 was a generous gift from Dr. Howard, Animal Research Center, UK. The plates were incubated at $4{ }^{\circ} \mathrm{C}$ overnight. The plates were then washed briefly with PBS Tween20 (0.05\%) and mouse anti bovine IL-10 labeled with biotin (Serotec Inc, Raleigh, NC) or rabbit anti 1 bovine TNFa (generous gift from Dr. Paape, USDA, Ames, IA) was added and incubated at $37^{\circ} \mathrm{C}$ for 3 hours.
Plates were then washed and streptavidin HRP (Serotec Inc, Raleigh, NC) was added to plates that were used for IL-10 detection, incubated for an hour at room temperature. Anti rabbit IgG1 labeled with HRP (Biorad, CA) was added to plates for detecting TNF $\alpha$ and incubated at room temperature for 2 hours. All the plates were then added with color developing solution (Biorad, CA) and plates were read using ELISA plate reader at $413 \mathrm{~nm}$.

\section{Estimation of protein concentration of IL- I 0 standard protein}

The standard protein used for quantitating IL-10 in culture supernatants was gifted by Dr. Howard, UK. The source of recombinant bovine IL-10 was culture supernatant obtained from Cos-7 cells transfected with a plasmid encoding bovine IL-10. The IL-10 supplied had 3000 biological units per ml. One biological unit of IL-10 supplied to us corresponded to an equivalent of $600 \mathrm{ng}$ of protein.

\section{Authors' contributions}

Dr. Janagama, performed cell infections, and analyzed the data. Dr. Jeong, helped in the design and analysis of ELISAs for cytokines studied. He also provided intellectual input during cell-infection study design. Dr. Kapur provided intellectual help during the study design and data analysis. Dr. Coussens was responsible for the original concept development with Dr. Sreevatsan. He also helped in the performance of MAP survival studies. Dr. Sreevatsan developed the concepts, designed MAP infection studies, and analyzed the data with Dr. Janagama. Dr. Sreevatsan also helped prepare the manuscript for consideration of publication.

\section{Acknowledgements}

This study was supported by state and federal funds appropriated to the Ohio Agricultural Research and Development Center (OARDC). We would like to thank the laboratory of Dr. Larry Schlesinger for helping optimize cell culture protocols used in this study. Mycobacterial research in SS laboratory is supported by funds from Johne's Disease Integrated Research Program and funds from USDA-NRI (Animal Protection).

\section{References}

I. Muskens J, Bakker D, de Boer J, van Keulen L: Paratuberculosis in sheep: its possible role in the epidemiology of paratuberculosis in cattle. Vet Microbiol 200I, 78(2): I0I-I09.

2. Pavlik I, Bejckova L, Pavlas M, Rozsypalova Z, Koskova S: Characterization by restriction endonuclease analysis and DNA hybridization using IS900 of bovine, ovine, caprine and human dependent strains of Mycobacterium paratuberculosis isolated in various localities. Vet Microbiol 1995, 45(4):3II-3I8.

3. Whittington RJ, Marsh IB, Whitlock RH: Typing of IS I3 I I polymorphisms confirms that bison (Bison bison) with paratuberculosis in Montana are infected with a strain of Mycobacterium avium subsp. paratuberculosis distinct from that occurring in cattle and other domesticated livestock. Mol Cell Probes 200I, I 5(3): 139-I45.

4. Ghadiali AH, Strother M, Naser SA, Manning EJ, Sreevatsan S: Mycobacterium avium subsp. paratuberculosis strains isolated from Crohn's disease patients and animal species exhibit 
similar polymorphic locus patterns. I Clin Microbiol 2004 42(I I):5345-5348.

5. Nau GJ, Richmond JF, Schlesinger A, Jennings EG, Lander ES, Young RA: Human macrophage activation programs induced by bacterial pathogens. Proc Natl Acad Sci U S A 2002, 99(3): $1503-1508$.

6. Hoal-van Helden EG, Stanton LA, Warren R, Richardson M, van Helden PD: Diversity of in vitro cytokine responses by human macrophages to infection by mycobacterium tuberculosis strains. Cell Biol Int 200I, 25(I):83-90.

7. Blumenthal A, Lauber J, Hoffmann R, Ernst M, Keller C, Buer J, Ehlers $\mathrm{S}$, Reiling $\mathrm{N}$ : Common and unique gene expression signatures of human macrophages in response to four strains of Mycobacterium avium that differ in their growth and persistence characteristics. Infect Immun 2005, 73(6):3330-334I.

8. Manca C, Reed MB, Freeman S, Mathema B, Kreiswirth B, Barry CE, Kaplan G: Differential monocyte activation underlies strainspecific Mycobacterium tuberculosis pathogenesis. Infect Immun 2004, 72(9):55| I-55I4.

9. McGarvey JA, Wagner D, Bermudez LE: Differential gene expression in mononuclear phagocytes infected with pathogenic and non-pathogenic mycobacteria. Clin Exp Immunol 2004, I 36(3):490-500.

10. Theus SA, Cave MD, Eisenach KD: Activated THP-I cells: an attractive model for the assessment of intracellular growth rates of Mycobacterium tuberculosis isolates. Infect Immun 2004, 72(2): II69-1 I73.

1I. Theus SA, Cave MD, Eisenach KD: Intracellular macrophage growth rates and cytokine profiles of Mycobacterium tuberculosis strains with different transmission dynamics. J Infect Dis 2005, I 9 I(3):453-460.

12. Stabel JR, Stabel TJ: Immortalization and characterization of bovine peritoneal macrophages transfected with SV40 plasmid DNA. Vet Immunol Immunopathol I995, 45(3-4):2 II-220.

13. Alzuherri HM, Woodall CJ, Clarke CJ: Increased intestinal TNFalpha, IL-I beta and IL-6 expression in ovine paratuberculosis. Vet Immunol Immunopathol 1996, 49(4):331-345.

14. Adams JL, Czuprynski CJ: Ex vivo induction of TNF-alpha and IL6 mRNA in bovine whole blood by Mycobacterium paratuberculosis and mycobacterial cell wall components. Microb Pathog 1995, 19(1): 19-29.

15. Coussens PM, Jeffers A, Colvin C: Rapid and transient activation of gene expression in peripheral blood mononuclear cells from Johne's disease positive cows exposed to Mycobacterium paratuberculosis in vitro. Microb Pathog 2004, 36(2):93-108

16. Friedland JS, Shaw TC, Price NM, Dayer JM: Differential regulation of MMP-I/9 and TIMP-I secretion in human monocytic cells in response to Mycobacterium tuberculosis. Matrix Biol 2002, 2I(I): $103-110$.

17. Weiss DJ, Evanson OA, Deng M, Abrahamsen MS: Gene expression and antimicrobial activity of bovine macrophages in response to Mycobacterium avium subsp. paratuberculosis. Vet Pathol 2004, 4I(4):326-337.

18. Coussens PM, Colvin CJ, Rosa GJ, Perez Laspiur J, Elftman MD: Evidence for a novel gene expression program in peripheral blood mononuclear cells from Mycobacterium avium subsp. paratuberculosis-infected cattle. Infect Immun 2003, 7 I (I I):6487-6498.

19. Motiwala AS, Amonsin A, Strother M, Manning EJ, Kapur V, Sreevatsan S: Molecular epidemiology of Mycobacterium avium subsp. paratuberculosis isolates recovered from wild animal species. J Clin Microbiol 2004, 42(4): I 703-17I2.

20. Whittington RJ, Taragel CA, Ottaway S, Marsh I, Seaman J, Fridriksdottir V: Molecular epidemiological confirmation and circumstances of occurrence of sheep (S) strains of Mycobacterium avium subsp. paratuberculosis in cases of paratuberculosis in cattle in Australia and sheep and cattle in Iceland. Vet Microbiol 200I, 79(4):311-322.

2I. Weiss DJ, Evanson OA, Moritz A, Deng MQ, Abrahamsen MS: Differential responses of bovine macrophages to Mycobacterium avium subsp. paratuberculosis and Mycobacterium avium subsp. avium. Infect Immun 2002, 70( I 0):5556-556I.

22. Zurbrick BG, Czuprynski CJ: Ingestion and intracellular growth of Mycobacterium paratuberculosis within bovine blood monocytes and monocyte-derived macrophages. Infect Immun 1987, 55(7):1588-1593

23. Tessema MZ, Koets AP, Rutten VP, Gruys E: How does Mycobacterium avium subsp. paratuberculosis resist intracellular degradation? Vet $Q$ 200I, 23(4):153-162.

24. Momotani E, Whipple DL, Thiermann AB, Cheville NF: Role of $M$ cells and macrophages in the entrance of Mycobacterium paratuberculosis into domes of ileal Peyer's patches in calves. Vet Pathol 1988, 25(2): I3I-137.

25. Sager H, Davis WC, Jungi TW: Bovine monocytoid cells transformed to proliferate cease to exhibit lineage-specific functions. Vet Immunol Immunopathol 1999, 68(2-4): I 13-130.

26. Weiss DJ, Evanson OA, McClenahan DJ, Abrahamsen MS, Walcheck BK: Regulation of expression of major histocompatibility antigens by bovine macrophages infected with Mycobacterium avium subsp. paratuberculosis or Mycobacterium avium subsp. avium. Infect Immun 200I, 69(2): I002-1008.

27. Bogdan C, Vodovotz Y, Nathan C: Macrophage deactivation by interleukin 10. J Exp Med I991, I 74(6): I549-I555.

28. Eriks IS, Emerson CL: Temporal effect of tumor necrosis factor alpha on murine macrophages infected with Mycobacterium avium. Infect Immun 1997, 65(6):2100-2106.

29. Kindler V, Sappino AP, Grau GE, Piguet PF, Vassalli P: The inducing role of tumor necrosis factor in the development of bactericidal granulomas during BCG infection. Cell 1989, 56(5):73|-740.

30. Sano C, Sato K, Shimizu T, Kajitani H, Kawauchi H, Tomioka H: The modulating effects of proinflammatory cytokines interferongamma (IFN-gamma) and tumour necrosis factor-alpha (TNF-alpha), and immunoregulating cytokines IL- 10 and transforming growth factor-beta (TGF-beta), on anti-microbial activity of murine peritoneal macrophages against Mycobacterium avium-intracellulare complex. Clin Exp Immunol 1999, II 5(3):435-442.

3I. Khalifeh MS, Stabel JR: Effects of gamma interferon, interleukin10 , and transforming growth factor beta on the survival of Mycobacterium avium subsp. paratuberculosis in monocytederived macrophages from naturally infected cattle. Infect Immun 2004, 72(4): 1974-1982.

32. Langelaar MF, Hope JC, Rutten VP, Noordhuizen JP, van Eden W, Koets AP: Mycobacterium avium ssp. paratuberculosis recombinant heat shock protein $\mathbf{7 0}$ interaction with different bovine antigen-presenting cells. Scand J Immunol 2005, 6I(3):242-250

33. Motiwala AS, Strother M, Amonsin A, Byrum B, Naser SA, Stabel JR, Shulaw WP, Bannantine JP, Kapur V, Sreevatsan S: Molecular epidemiology of Mycobacterium avium subsp. paratuberculosis: evidence for limited strain diversity, strain sharing, and identification of unique targets for diagnosis. J Clin Microbiol 2003, 4I(5):20I5-2026

34. Motiwala AS, Strother M, Theus NE, Stich RW, Byrum B, Shulaw WP Kapur V, Sreevatsan S: Rapid Detection and Typing of Strains of Mycobacterium avium subsp. paratuberculosis from Broth Cultures. J Clin Microbiol 2005, 43(5):2 I I I-2 I I 7

35. Snoek-van Beurden PA, Von den Hoff JW: Zymographic techniques for the analysis of matrix metalloproteinases and their inhibitors. Biotechniques 2005, 38(1):73-83.

36. Brew K, Dinakarpandian D, Nagase $\mathrm{H}$ : Tissue inhibitors of metalloproteinases: evolution, structure and function. Biochim Biophys Acta 2000, 1477(I-2):267-283.

37. Coussens PM, Pudrith CB, Skovgaard K, Ren X, Suchyta SP, Stabel JR, Heegaard PM: Johne's disease in cattle is associated with enhanced expression of genes encoding IL-5, GATA-3, tissue inhibitors of matrix metalloproteinases $I$ and 2 , and factors promoting apoptosis in peripheral blood mononuclear cells. Vet Immunol Immunopathol 2005, 105(3-4):22 I-234.

38. Quiding-Jarbrink M, Smith DA, Bancroft G]: Production of matrix metalloproteinases in response to mycobacterial infection. Infect Immun 200I, 69(9):566 I-5670.

39. Price NM, Gilman RH, Uddin J, Recavarren S, Friedland JS: Unopposed matrix metalloproteinase-9 expression in human tuberculous granuloma and the role of TNF-alpha-dependent monocyte networks. J Immunol 2003, I 7 I ( I0):5579-5586.

40. Coussens PM, Colvin CJ, Wiersma K, Abouzied A, Sipkovsky S: Gene expression profiling of peripheral blood mononuclear cells 
from cattle infected with Mycobacterium paratuberculosis. Infect Immun 2002, 70(10):5494-5502.

41. Livak KJ, Schmittgen TD: Analysis of relative gene expression data using real-time quantitative PCR and the 2(-Delta Delta C(T)) Method. Methods 200I, 25(4):402-408.

42. Coussens PM, Verman N, Coussens MA, Elftman MD, McNulty AM: Cytokine Gene Expression in Peripheral Blood Mononuclear Cells and Tissues of Cattle Infected with Mycobacterium avium subsp. paratuberculosis: Evidence for an Inherent Proinflammatory Gene Expression Pattern. Infect Immun 2004, 72(3): 1409-1422.

43. Paape MJ, Rautiainen PM, Lilius EM, Malstrom CE, Elsasser TH: Development of anti-bovine TNF-alpha mAb and ELISA for quantitating TNF-alpha in milk after intramammary injection of endotoxin. J Dairy Sci 2002, 85(4):765-773.

44. Kwong LS, Hope JC, Thom ML, Sopp P, Duggan S, Bembridge GP, Howard C]: Development of an ELISA for bovine IL-10. Vet Immunol Immunopathol 2002, 85(3-4):2 I3-223.

Publish with Biomed Central and every scientist can read your work free of charge

"BioMed Central will be the most significant development for disseminating the results of biomedical research in our lifetime. "

Sir Paul Nurse, Cancer Research UK

Your research papers will be:

- available free of charge to the entire biomedical community

- peer reviewed and published immediately upon acceptance

- cited in PubMed and archived on PubMed Central

- yours - you keep the copyright

Submit your manuscript here:

http://www.biomedcentral.com/info/publishing_adv.asp
BioMedcentral 